\title{
Bacterial Tracheitis
}

National Cancer Institute

\section{Source}

National Cancer Institute. Bacterial Tracheitis. NCI Thesaurus. Code C78647.

Bacterial infectious process with formation of mucopurulent membranes affecting the trachea. Causative agents include Staphylococcus, Streptococcus, Haemophilus influenzae, Pseudomonas, and Klebsiella. 